\title{
Diethylaminoethyl Cellulose Immobilized Pointed Gourd (Trichosanthes dioica) Peroxidase in Decolorization of Synthetic Dyes
}

\section{Farrukh Jamal'* and Tanvi Goel ${ }^{2}$}

${ }^{1}$ Department of Biochemistry, Dr. Ram Manohar Lohia Avadh University, Faizabad-224001, U.P., India

${ }^{2}$ Division of Life Sciences, Research Centre, Nehru Gram Bharti University, Jhunsi, Allahabad-221505, U.P., India

\begin{abstract}
Diethylaminoethyl (DEAE) cellulose adsorbed Pointed Gourd Peroxidase (PGP) was employed in decolorization of synthetic dyes. The expressed activity of immobilized preparation on fifth repeated use was $\sim 50 \%$ and decolorization achieved for synthetic dyes DR19 and dye mixture (DR19+DB9) was $64.9 \%$ and $61.5 \%$ respectively. Immobilized enzyme could effectively decolorize up to $88.2 \%$ and $77.4 \%$ of DR 19 and dye mixture respectively in stirred batch process at $40^{\circ} \mathrm{C}$ whereas dye color removal monitored at $30^{\circ} \mathrm{C}$ and $50^{\circ} \mathrm{C}$ was comparatively low under similar conditions. Immobilized enzyme in the packed column used for the continuous removal of dye color could successfully decolorize DR19 and dye mixture to $69.4 \%$ and $51.4 \%$ after 50 d of operation. Thus, DEAE immobilized PGP is a simple, economical and effective preparation to remove color of synthetic dyes.
\end{abstract}

Keywords: Pointed gourd peroxidase; Diethylaminoethyl; Immobilization; Dye decolorization; Continuous reactor

\section{Introduction}

The waste water from dye industries is rich in compounds that are toxic and detrimental to different life forms including humans. Color is usually the first contaminant to be recognized which affects the aesthetic merit, transparency and gas solubility of water bodies. The unused synthetic dyes in textile effluent mostly go untreated in the river and water bodies. Disperse dyes constitute the largest group of colorants used in the industry and are difficult to remove by chemical treatment. The processes involving physical and chemical treatment for decolorization of textile wastewater have numerous operational problems, and involve high cost [1]. On the other hand, most of the synthetic dyes are xenobiotic compounds which are poorly removed by the use of conventional biological aerobic treatments [2].

The dye color removal from wastewater is an area of technological innovations. In recent times, the approach has shifted towards enzyme based treatment of colored wastewater/industrial effluents. Enzymes are vital to new processes as they are environmental friendly and are capable of specifically reducing hazardous wastes. Peroxidases (EC 1.11.1.7) are a group of heme-containing enzymes that have been isolated from diverse sources including plants, animals and microorganisms $[3,4]$. These enzymes have the ability to act on a number of aromatic compounds in the presence of hydrogen peroxide. The function of the latter is to oxidize the enzyme into its catalytically active form which in turn is capable of reacting with the phenolic contaminants [4]. However, during the reaction process these enzymes get inactivated and this inactivation might be due to the free radical formation during enzymatic reaction. These radicals are adsorbed on the enzymes active site thus, blocking the substrate binding sites [5].

Peroxidases are very useful in either removal of recalcitrant toxic compounds or transforming them into innocuous products. They can change the characteristics of a given waste rendering it more amenable for treatment [6]. Their catalytic action is extremely efficient and selective as opposed to chemical catalysts due to higher reaction rates, milder reaction conditions (relatively low temperature and in the entire aqueous phase $\mathrm{pH}$ range) and greater stereo specificity [7]. Though much attention has been paid in the utilization of biocatalysts in several fields, their involvement has been felt very recently in solving the environmental problems $[8,9]$. The use of free enzymes poses inherent limitations as the stability and catalytic ability of free enzymes decreases with the complexity of the effluents [10]. Some of these limitations are overcome by the use of enzymes in immobilized form which can be used as catalysts with long lifetime [10,11].

An extensive work has been done on the enzymatic removal of aromatic compounds from wastewater by using peroxidase and hydrogen peroxide [12]. Enzymatic method has some advantages over conventional methods of treatment which include: applicability over a broad range of $\mathrm{pH}$, temperature, salinity and contaminant concentration, action on recalcitrant materials and simplicity in controlling the process [13]. However, an effective use of enzymes was hampered due to their non-reusability, sensitivity to various denaturants and high cost [14]. Some of these constraints may be overcome by immobilizing enzymes on various supports $[15,16]$.

Work in the area of enzyme technology has provided significant clues that facilitate using enzymes optimally at large scale by cross-linking, entrapping and immobilizing $[17,18]$. The current study demonstrates a simple, inexpensive and high yield procedure for immobilization of Pointed Gourd Peroxidase (PGP) on DEAE cellulose for the dye color removal of disperses dyes. The decolorization of disperse dyes was done in batch process as well as in a continuous vertical bed-reactor. The reusability of the I-PGP for dye color removal was measured.

\section{Material and Methods}

\section{Materials}

Bovine serum albumin, $o$-dianisidine $\mathrm{HCl}$, Disperse Red 19

*Corresponding author: Farrukh Jamal, Assistant Professor, Department of Biochemistry (DST-FIST \& UGC-SAP Supported), Dr. Ram Manohar Lohia Avadh University, Faizabad-224001, U.P., India, Fax: +91-05278-246330; E-mail: farrukhrmlau@gmail.com or journal.farrukh@gmail.com

Received November 03, 2014; Accepted November 26, 2014; Published December 01, 2014

Citation: Jamal F, Goel T (2014) Diethylaminoethyl Cellulose Immobilized Pointed Gourd (Trichosanthes dioica) Peroxidase in Decolorization of Synthetic Dyes. J Bioprocess Biotech 4: 187 doi: 10.4172/2155-9821.1000187

Copyright: $\odot 2014$ Jamal F, et al. This is an open-access article distributed under the terms of the Creative Commons Attribution License, which permits unrestricted use, distribution, and reproduction in any medium, provided the original author and source are credited. 
(DR19), Disperse Black 9 (DB9), DEAE cellulose, glutaraldehyde was procured from Sigma Chemical Co. (St. Louis, MO, USA). All other chemicals were of analytical grade. The pointed gourds were procured from local market.

\section{Partial purification of PGP by ammonium sulphate precipitation}

The protein was extracted from pointed gourd using ammonium sulphate as described previously [19]. This preparation of protein was aliquoted and stored for further use.

\section{Protein estimation and assay of peroxidase (PGP) activity}

Protein was estimated using the procedure of Lowry et al. [20]. The salt purified protein was assayed for peroxidase activity as describe by Jamal et al. [21,22]. Peroxidase activity was measured by the change in the optical density $(\lambda=460 \mathrm{~nm})$ at $37^{\circ} \mathrm{C}$, by estimating the initial rate of oxidation of $6.0 \mathrm{mM} o$-dianisidine $\mathrm{HCl}$ in presence of $18.0 \mathrm{mM} \mathrm{H}_{2} \mathrm{O}_{2}$ in $0.1 \mathrm{M}$ sodium acetate buffer ( $\mathrm{pH}$ 5.6) for $15 \mathrm{~min}$. Immobilized enzyme preparation was continuously agitated for entire duration of assay. One unit $(1.0 \mathrm{U})$ of peroxidase activity was defined as the amount of enzyme protein that catalyzes the oxidation of $1 \mathrm{mmol}$ of $o$-dianisidine $\mathrm{HCl}$ in the presence of $\mathrm{H}_{2} \mathrm{O}_{2}$ per min at $37^{\circ} \mathrm{C}$ into colored product $\left(\varepsilon_{\mathrm{m}}=30\right.$ $\left.000 \mathrm{M}^{-1} \mathrm{~L}^{-1}\right)$

\section{Treatment and activation of DEAE cellulose}

The activation of DEAE cellulose was done using method described elsewhere [17,23]. Briefly $6.0 \mathrm{~g}$ of DEAE cellulose was gently stirred and allowed to swell overnight in $150 \mathrm{~mL}$ of distilled water. The swollen DEAE cellulose was filtered with a Buchner Funnel and incubated with $120 \mathrm{~mL}$ of $0.5 \mathrm{~N} \mathrm{HCl}$ for $1 \mathrm{~h}$. Acid treated DEAE cellulose was collected by filtration on Buchner Funnel and was washed with distilled water continuously till it attained $\mathrm{pH} 7.0 .125 \mathrm{~mL}$ of $0.5 \mathrm{~N} \mathrm{NaOH}$ was added to $\mathrm{HCl}$ treated DEAE cellulose and it was stirred on a magnetic stirrer for $1 \mathrm{~h}$ at $4^{\circ} \mathrm{C}$. The treated ion exchanger was washed again with distilled water till it attained neutral $\mathrm{pH}$. Further, it was suspended and stored in $100 \mathrm{~mL}$ of distilled water at $4^{\circ} \mathrm{C}$.

\section{Cross-linking of DEAE cellulose adsorbed PGP}

PGP (1300 units) was added to $1.2 \mathrm{~g}$ of DEAE cellulose and stirred overnight at $4^{\circ} \mathrm{C}$. The preparation was treated with $0.3 \%(\mathrm{v} / \mathrm{v})$ glutaraldehyde for $2 \mathrm{~h}$ at $4^{\circ} \mathrm{C}$ with constant stirring. Cross-linking was performed in presence of $o$-dianisidine $\mathrm{HCl}$. Ethanolamine was added to a final concentration of $0.01 \%(\mathrm{v} / \mathrm{v})$ to stop cross-linking. The solution was allowed to stand for $90 \mathrm{~min}$ at room temperature and the pellet was collected by centrifugation at $3000 \times \mathrm{g}$ for $30 \mathrm{~min}$ on a cooling centrifuge $4^{\circ} \mathrm{C}[24,25]$.

\section{Preparation of synthetic dye solutions and calculation of percent dye decolorization}

The synthetic solutions of disperse dyes $(30-50 \mathrm{mg} / \mathrm{mL})$ were prepared in distilled water to examine their decolorization by soluble and immobilized PGP. A mixture of disperse dyes consisting of DR19 and DB9 was prepared by mixing each dye in equal proportion of color intensity [26]. To compare various experiments, the decolorization was calculated for each dye or mixture of dyes. Dye decolorization was monitored by measuring the difference at the maximum absorbance for each dye as compared with control experiments without enzyme on UV-visible spectrophotometer (JASCO V-550, Japan). Untreated dye solution (inclusive of all reagents except the enzymes) was used as control for calculation of percent decolorization. The dye decolorization was calculated as the ratio of the difference of absorbance of treated and untreated dye to that of treated dye and converted in terms of percentage. Three independent experiments were carried out in duplicate and the mean was calculated.

\section{Reusability of immobilized PGP in the decolorization of disperse dye}

DR19 and mixture of dyes (DR19+DB9) were incubated with immobilized PGP for $2 \mathrm{~h}$ as mentioned earlier. The enzyme was separated by centrifugation and stored in the assay buffer for over $12 \mathrm{~h}$. Experiments was repeated upto 10 times with the same preparation of PGP and each time with a fresh batch of dye solution. Dye decolorization was monitored at specific wavelength maxima of the dye solutions. The percent decolorization was calculated by taking untreated dye or mixture of dyes as control (100\%).

\section{Decolorization of dye solution by soluble and immobilized peroxidase in batch processes}

The dye solution $(200 \mathrm{~mL})$ was treated with soluble and immobilized PGP $(180 \mathrm{U})$ in $100 \mathrm{mM}$ sodium acetate buffer, pH 5.6 in the presence of $0.2 \mathrm{mM}$ riboflavin as redox mediator and $0.8 \mathrm{mM} \mathrm{H}_{2} \mathrm{O}_{2}$ for different durations and at varying temperatures [21] . The treated samples were centrifuged at $3000 \times \mathrm{g}$ for $15 \mathrm{~min}$. The residual dye concentration was measured spectrophotometrically at specific wavelength maxima of the dye. Untreated dye solution was considered as control (100\%) for the calculation of percent decolorization.

\section{Continuous dye decolorization using a vertical PGP- immobilized column}

A packed bed-reactor system was developed for the continuous removal of dyes from solutions. A column $(15 \times 2.0 \mathrm{~cm})$ was filled with DEAE cellulose immobilized PGP (1500 U) and equilibrated with 100 $\mathrm{mM}$ sodium acetate buffer $\mathrm{pH}$ 5.6. The flow rate was maintained at 12 $\mathrm{mL} \mathrm{h}^{-1}$ and the feed solution contained either DR19 or mixture of DR19 and DB9 in two independent reactor systems. Dye solutions were run under the same experimental conditions. Reactors were operated at room temperature $\left(37^{\circ} \mathrm{C}\right)$ for a period of 60 days. Treated samples were collected at an interval of $10 \mathrm{~d}$ and the absorbance of each sample was recorded.

\section{Results}

\section{Reusability and storage stability of DEAE-PGP complex in dye decolorization}

Table 1 shows the expressed activity of DEAE-PGP complex. Immobilized PGP (I-PGP) expressed 50\% activities after being repeatedly use for five times. Thereafter, the expressed peroxidase activity declined progressively to $15.5 \%$ in the tenth use. I-PGP preparation was used to remove the dye color of disperse dye DR19 and dye mixture (DR19 and DB9). The decolorizing ability of I-PGP was $51.4 \%$ for DR19 in the eight repeated use whereas the dye mixture (DR19+DB9) showed 51.7\% decolorization in the seventh repeated use. Thereafter, decolorizing potential of I-PGP underwent downfall progressively and was parallel to the decline in the expressed peroxidase activity of the I-PGP preparation.

Storage stability along with the potential to remove the dye color was monitored upto $60 \mathrm{~d}$ with an interval of 5 to $10 \mathrm{~d}$. Table 2 shows the remaining activity in the stored preparations and their ability to remove the dye color. The $35 \mathrm{~d}$ stored I-PGP preparation expressed $53.4 \%$ peroxidase activity and decolorized DR19 and dye mixture (DR19+DB9) 
to $73.5 \%$ and $59.9 \%$ respectively. Thereafter the decolorization potential underwent downfall with the $60 \mathrm{~d}$ stored preparation expressing poor peroxidase activity (23.8\%) and removed dye color to $29.3 \%$ (DR19) and $22.6 \%$ (DR19+DB 9).

\section{Dye treatment in a stirred batch process at varying time and temperature}

The decolorization of dyes by soluble and DEAE immobilized PGP was carried out at varying time durations and temperatures as shown in Table 3. It was observed that maximum dye color removal was

\begin{tabular}{|c|c|c|c|}
\hline \multirow{2}{*}{$\begin{array}{l}\text { No of uses } \\
\text { of DEAE-PGP } \\
\text { complex }\end{array}$} & \multirow{2}{*}{$\begin{array}{l}\text { Expressed } \\
\text { peroxidase } \\
\text { activity (\%) }\end{array}$} & \multicolumn{2}{|c|}{ Percent dye decolorization } \\
\hline & & $\begin{array}{l}\text { DR19 } \\
\left(\lambda_{495 \mathrm{~nm}}\right)\end{array}$ & $\begin{array}{c}\text { DR19 and DB9 } \\
\left(\lambda_{460 \mathrm{~nm}}\right)\end{array}$ \\
\hline 1 & 89.7 & 91.5 & 82.2 \\
\hline 2 & 78.8 & 87.4 & 80.6 \\
\hline 3 & 69.7 & 74.6 & 72.7 \\
\hline 4 & 58.4 & 69.8 & 65.4 \\
\hline 5 & 50.7 & 64.9 & 61.5 \\
\hline 6 & 42.4 & 60.6 & 59.4 \\
\hline 7 & 36.3 & 58.9 & 51.8 \\
\hline 8 & 29.7 & 51.4 & 43.2 \\
\hline 9 & 18.9 & 33.6 & 28.5 \\
\hline 10 & 15.5 & 21.4 & 19.6 \\
\hline
\end{tabular}

Table 1: Re-usability of DEAE-immobilized PGP in decolourization of dye and dye mixture. Immobilized PGP was independently incubated with DR19 and mixture of dyes (DR19+DB9) $(150 \mathrm{~mL})$ at $40^{\circ} \mathrm{C}$. Dye decolourization was determined after incubation period of $2 \mathrm{~h}$. The immobilized enzyme was collected by centrifugation $(3000 \times \mathrm{g})$ and stored in assay buffer at $4^{\circ} \mathrm{C}$ overnight. The similar experiment was repeated 10 times. Each value represents the mean for three independent experiments performed in duplicate.

\begin{tabular}{|c|c|c|c|}
\hline \multicolumn{2}{|c|}{ Storage stability of I-PGP complex } & \multicolumn{2}{|c|}{ Dye colour removal (\%) } \\
\hline Days (d) & Remaining Activity (\%) & DR19 $\left(\boldsymbol{(}_{\mathbf{4 9 5 n m}}\right)$ & DR19 and DB9 $\left.\boldsymbol{(}_{\mathbf{4 6 0 n m}}\right)$ \\
\hline 5 & 91.5 & 89.8 & 76.7 \\
\hline 10 & 76.8 & 88.7 & 74.3 \\
\hline 15 & 74.6 & 87.4 & 73.6 \\
\hline 20 & 69.8 & 85.9 & 73.2 \\
\hline 25 & 67.5 & 83.3 & 71.4 \\
\hline 30 & 61.9 & 77.9 & 69.7 \\
\hline 35 & 53.4 & 73.5 & 59.9 \\
\hline 40 & 45.3 & 67.2 & 56.2 \\
\hline 50 & 34.5 & 53.8 & 41.7 \\
\hline 60 & 23.8 & 29.3 & 22.6 \\
\hline
\end{tabular}

Table 2: Storage stability of DEAE- immobilized PGP preparations. Expressed activity is the activity achieved after immobilization. Original activity is the activity of soluble counterparts and taken as $100 \%$. achieved at $40^{\circ} \mathrm{C}$ with an exposure time of $2 \mathrm{~h}$. Soluble PGP decolorized $80.9 \%$ and $74.1 \%$ of DR19 and mixture of dyes after $2 \mathrm{~h}$ of incubation, respectively. However, DEAE immobilized PGP was more effective and sustainable as compared to its soluble counterpart in the decolorization of both DR19 and mixture of dyes. Decolorization by I- PGP under similar conditions was $88.2 \%$ and $77.4 \%$ for DR19 and dye mixture respectively after $2 \mathrm{~h}$ of treatment. At lower temperature of $30^{\circ} \mathrm{C}$, the performance of soluble PGP were lower with $76.9 \%$ and $55.1 \%$ dye color removal achieved after an incubation period of $2 \mathrm{~h}$. However under similar conditions the I-PGP was much effective and decolorized DR19 and dye mixture to an extent of $78.4 \%$ and $65.4 \%$ respectively. Further, at $50^{\circ} \mathrm{C}$ and under similar conditions of incubation soluble PGP effectively removed the dye color of DR19 (55.9\%) and dye mixture $(51.2 \%)$. On increasing the incubation time $(160 \mathrm{~min})$, the dye color removal by soluble PGP was lowered to $31.3 \%$ (DR19) and $29.4 \%$ (DR19+DB9) whereas the performance of I-PGP was sufficiently higher $48.1 \%$ (DR19) and 60.2\% (DR19+BB9). It was also observed that although, the optimum temperature was $40^{\circ} \mathrm{C}$, yet I-PGP still retained sufficient potential at $50^{\circ} \mathrm{C}$ as compared to that recorded at $30^{\circ} \mathrm{C}$.

\section{Dye decolorization in a packed vertical I- PGP column}

Table 4 shows the dye color removal of DR19 and mixture of dyes (DR19+DB9) by passing through I-PGP packed vertical bed reactor. About $88.5 \%$ and $74.5 \%$ of dye decolorization was achieved even after $10 \mathrm{~d}$ of its continuous operation. With the increase in the duration of continuous operation there was decrease in the decolorization ability of the I-PGP packed column. On $30 \mathrm{~d}$ of continuous use I-PGP decolorized DR19 (77.4\%) and dye mixture (69.5\%). This decrease continued to $60 \mathrm{~d}$ with only $50.5 \%$ and $53.4 \%$ dye color recorded for DR19 and dye mixture respectively.

\section{Discussion}

Immobilizing enzymes directly from crude homogenate is relatively a cost-effective and seemingly a feasible approach [27]. Although the immobilized form of bio-molecules holds commercial importance, protocols available for such preparations are limited. Immobilization by adsorption is an effective procedure for binding enzymes directly from partially purified preparations or even from crude homogenates [24]. The present study was aimed to immobilize PGP on a support which could be used to treat disperse dyes and dye mixtures which are generally present in textile effluents.

DEAE cellulose adsorbed PGP was cross-linked with glutaraldehyde and this preparation was found to be very efficient in removing the dye colors of disperse dyes viz., DR19 and dye mixture (DR19+DB9). I-PGP

\begin{tabular}{|c|c|c|c|c|c|c|c|c|c|c|c|c|}
\hline \multirow{4}{*}{ Time (min) } & \multicolumn{12}{|c|}{ Percent Dye decolourization at varying temperatures at } \\
\hline & \multicolumn{4}{|c|}{$30^{\circ} \mathrm{C}$} & \multicolumn{4}{|c|}{$40^{\circ} \mathrm{C}$} & \multicolumn{4}{|c|}{$50^{\circ} \mathrm{C}$} \\
\hline & \multicolumn{2}{|c|}{$\begin{array}{c}\text { DR19 } \\
\left(\lambda_{495 \mathrm{~nm}}\right)\end{array}$} & \multicolumn{2}{|c|}{ DR19+ DB9 $\left(\lambda_{460 \mathrm{~nm}}\right)$} & \multicolumn{2}{|c|}{$\begin{array}{c}\text { DR19 } \\
\left(\lambda_{495 \mathrm{~nm}}\right)\end{array}$} & \multicolumn{2}{|c|}{ DR19+ DB9 $\left(\lambda_{460 \mathrm{~nm}}\right)$} & \multicolumn{2}{|c|}{$\begin{array}{c}\text { DR19 } \\
\left(\lambda_{495 \mathrm{~mm}}\right)\end{array}$} & \multicolumn{2}{|c|}{ DR19+ DB9 } \\
\hline & S- PGP & I-DEAE & S-PGP & I-DEAE & S- PGP & I-DEAE & S-PGP & I-DEAE & S- PGP & I-DEAE & S-PGP & I-DEAE \\
\hline 20 & 70.8 & 72.5 & 59.2 & 62.5 & 74.8 & 76.5 & 66.2 & 70.5 & 61.8 & 62.5 & 46.2 & 61.5 \\
\hline 40 & 70.6 & 72.6 & 58.7 & 63.6 & 74.6 & 78.4 & 67.7 & 72.6 & 61.6 & 62.6 & 48.7 & 62.6 \\
\hline 60 & 72.8 & 74.4 & 57.4 & 65.5 & 78.8 & 81.3 & 69.4 & 73.5 & 60.8 & 64.4 & 49.4 & 65.5 \\
\hline 80 & 73.6 & 76.4 & 54.5 & 65.5 & 79.9 & 86.4 & 71.5 & 75.5 & 60.6 & 66.4 & 53.5 & 67.5 \\
\hline 100 & 73.7 & 76.4 & 54.6 & 65.4 & 79.9 & 86.9 & 72.4 & 77.4 & 58.7 & 66.4 & 55.6 & 67.9 \\
\hline 120 & 76.9 & 78.4 & 55.1 & 65.4 & 80.9 & 88.2 & 74.1 & 77.4 & 55.9 & 58.4 & 51.2 & 63.4 \\
\hline 140 & 60.4 & 72.2 & 33.2 & 64.3 & 65.4 & 88.1 & 45.2 & 69.3 & 47.4 & 58.2 & 36.2 & 63.3 \\
\hline 160 & 50.3 & 69.1 & 30.4 & 60.2 & 52.7 & 88.3 & 39.8 & 69.1 & 31.3 & 48.1 & 29.4 & 60.2 \\
\hline
\end{tabular}

Table 3: Dye decolourization in batch processes. DR 19 or mixture of dyes (DR19+DB9) (200 mL) was independently treated with soluble and immobilized PGP (180 U) for varying times and temperatures in batch processes. Aliquots were taken from containers at different time intervals for measuring the dye colour removal. Each value represents the mean for three independent experiments. 


\begin{tabular}{|c|c|c|}
\hline \multirow{2}{*}{ No of days (d) } & $\begin{array}{c}\text { DR19 } \\
\left(\boldsymbol{\lambda}_{495 \mathrm{~mm}}\right)\end{array}$ & DR19+ DB9 $\left(\boldsymbol{(}_{\mathbf{4 6 0 \mathrm { nm }}}\right)$ \\
\hline \multirow{2}{*}{10} & I-PGP & I-PGP \\
\hline 20 & 88.5 & 74.5 \\
\hline 30 & 85.6 & 73.6 \\
\hline 40 & 77.4 & 69.5 \\
\hline 50 & 77.8 & 68.5 \\
\hline 60 & 69.4 & 51.4 \\
\hline
\end{tabular}

Table 4: Continuous removal of dye colour in a vertical bed reactor. Dye / dye mixture were independently passed through the reactor $(15 \times 2 \mathrm{~cm})$ filled with I-PGP (1500 U) at room temperature continuously. Samples from the column outlet were collected and after centrifugation were analyzed spectrophotometrically for the dye colour removal.

could be used seven times to achieve dye color removal of DR19 and dye mixture to over $50 \%$ which is considerably effective than soluble peroxidases. Immobilized preparation of enzymes has advantage over free enzyme as it could be reused several times and may also provide a better environment for the catalytic activity of enzyme [14,28]. Moreover, such enzymes in immobilized states can be stored for longer durations and relatively easier to handle and use. The data of storage stability of I-PGP suggest that immobilized preparations confer long lasting peroxidase activity which could be used in reactors for the treatment of effluents containing phenolic and other aromatic pollutants including dyes which are primarily represented in textile effluents. The reusability and storage experiments further supported that the use of such a cheaper source of enzyme and support will definitely minimize the cost of immobilization and provide a suitable approach for the treatment of huge volumes of wastewater in batch processes as well as in continuous reactors.

In our earlier studies we have shown that the dye color removal was poor when these dyes were treated without enzyme or only in the presence of redox mediator or the enzyme alone. Thus it's essential that the enzyme catalytic activity is effective in conjunction with redox mediators and optimum concentration of hydrogen peroxide $[4,19]$. Further, the enzyme works well in acidic $\mathrm{pH}$ (usually in the range of 3 to 6) and therefore the study was performed at $\mathrm{pH} 5.6$ (data not shown). The decolorization data indicates that the enzyme retained sufficient activity in the immobilized state at the operational $\mathrm{pH}$.

The dyes tested may have a narrow redox potential range and perhaps a correlation exists between redox potential and dye reduction rates. It is known that the closer the redox potential is between dye and redox mediator, the faster is dye reduction, because electron transfer is facilitated due to the low potential difference. Such behavior explains the better catalytic properties of riboflavin. However, dye reduction rate is not only determined by redox potential, but also by other factors such as chemical structure, environmental conditions and anaerobic sludge affinity and concentration. The chromophore cleavage by PGP in conjunction with redox mediators was favorable for azo dyes, because the reduction occurs in the nitrogen bonds, which have more affinity to receive electrons, based on electronegative properties, as compared to carbon-carbon bond chromophore of the anthraquinone dyes. Therefore, the effect of redox mediators on dye reduction is related to the molecular structure, being more evident for azo dyes with low decolorization rates in the absence of these compounds, and ineffective for anthraquinone dyes because of the structural stability of the latter [26].

Our studies showed that immobilized peroxidase was much more effective in removing dye color as compared to soluble enzyme in a batch process. It may be due to the reason that immobilization shielded the number of reactive free amino groups, which are not protected in soluble case and hence, were more susceptible to reaction with the reactive products like free radicals [29]. Our findings are in accordance to our earlier studies using immobilized PGP-Concanavalin A complex on calcium alginate pectin gel in decolorization of synthetic dyes [24].

To evaluate the efficiency of immobilized PGP on a large scale for the removal of dye color, a vertical continuous reactor system was designed and operated continuously with a flow rate of $15 \mathrm{~mL} \mathrm{~h}^{-1}$. In this work, a flow rate of $15 \mathrm{~mL} \mathrm{~h}^{-1}$ was maintained to run the reactor without any operational problem like clogging which may be of concern since precipitate is formed during the enzymatic reaction. Both the reactors worked for more than $60 \mathrm{~d}$ approximately, thus explaining their efficiency towards dye decolorization. A significant loss of color appeared when DR19 or mixture of dyes was treated with I- PGP in the presence of redox mediator, riboflavin in a continuous reactor system. It has earlier been reported that the disappearance of peak in visible region was either due to the breakdown of chromophoric groups present in dyes or the removal of pollutants in the form of insoluble products [23].

One of the remarkable properties of the immobilized enzyme over its soluble counterpart was that it can be separated from the reaction mixture and hence, can be reused repeatedly to transform its substrate. Although PGP immobilized on DEAE cellulose was losing its activity over repeated uses, the decrease in efficiency of the enzyme after few cycles may be due to the binding of the active sites of the enzyme by the product produced during the enzymatic reactions [30].

\section{Conclusion}

The preparation and application of DEAE-immobilized pointed gourd peroxidase in decolorization of synthetic dyes was investigated. The data of the present work reveals the effectiveness of the immobilized peroxidase in sustainable dye color removal. The DEAE immobilized PGP expressed remarkable peroxidase activity, can be repeatedly used and stably stored for long periods. The system in this study is developed with a cheaper biocatalyst that is quite effective in treating dyes continuously in a small laboratory reactor. The enzymes in soluble form cannot be exploited on large scale due to their limitations of stability and reusability. Consequently, the use of immobilized enzymes has significant advantages over soluble enzymes. In the near future, cost effective, eco-friendly technologies based on the enzymatic approach for treatment of dyes present in the industrial effluents/wastewater will play a vital role. By immobilization using adsorption on DEAE, the apparent rate of enzyme inactivation was reduced which allowed a significant reduction in enzyme requirements for treatment. This increases enzyme lifetime which represents a very significant saving in terms of treatment costs.

\section{Acknowledgement}

We are thankful to the Department of Science and Technology (DST-FIST) under the Ministry of Science and Technology for providing financial assistance towards infrastructure development for carrying out this work. There is no conflict of interest whatsoever regarding this manuscript.

\section{References}

1. Jamal F, Qidwai T, Singh D, Pandey PK (2012) Biocatalytic activity of immobilized pointed gourd (Trichosanthes dioica) peroxidase-concanavalin A complex on calcium alginate pectin gel. J Mol Cat B: Enzy 74: 125-131.

2. Husain Q (2006) Potential applications of the oxidoreductive enzymes in the decolorization and detoxification of textile and other synthetic dyes from polluted water: a review. Crit Rev Biotechnol 26: 201-221. 
Citation: Jamal F, Goel T (2014) Diethylaminoethyl Cellulose Immobilized Pointed Gourd (Trichosanthes dioica) Peroxidase in Decolorization of Synthetic Dyes. J Bioprocess Biotech 4: 187 doi: 10.4172/2155-9821.1000187

3. Agostini E, Hernández-Ruiz J, Arnao MB, Milrad SR, Tigier HA et al. (2002) A peroxidase isoenzyme secreted by turnip (Brassica napus) hairy-root cultures: inactivation by hydrogen peroxide and application in diagnostic kits. Biotechnol Appl Biochem. 35: 1-7.

4. Jamal F, Qidwai T, PandeyPK, Singh D (2011) Catalytic potential of cauliflowe (Brassica oleracea) bud peroxidase in decolorization of synthetic recalcitrant dyes using redox mediator. Catal Commun 15: 93-98.

5. Bratkovskaja I, Vidziunaite R, Kulys J (2004) Oxidation of phenolic compounds by peroxidase in the presence of soluble polymers. Biochemistry (Mosc) 69: 985-992.

6. Karam J, Nicell JA (1997) Potential application of enzymes in waste treatment J Chem Tech Biotechnol 69: 141-153.

7. Mohan SV, Prasad KK, Prakasham RS, Sarma PN (2002) Enzymatic pretreatment to enhance the biodegradability of industrial wastewater. Chem Wkly 23:163-168

8. Mohan SV, Prasad KK, Rao NC, Sarma PN (2005) Acid azo dye degradation by free and immobilized horseradish peroxidase (HRP) catalyzed process. Chemosphere 58: 1097-1105.

9. Nicell JA (1994) Kinetics of horseradish peroxidase-catalysed polymerization and precipitation of aqueous 4-chlorophenol. J Chem Technol Biotechnol 60: 203-215.

10. Zille A, Tzanov T, Gübitz GM, Cavaco-Paulo A (2003) Immobilized laccase for decolourization of Reactive Black 5 dyeing effluent. Biotechnol Lett 25: 14731477.

11. Rogalski J, Jozwik E, Hatakka A, Leonomicz A (1995) Immobilization of laccase from Phlebia radiata on controlled porosity glass. J Mol Catal B: Enzy 95: 99108.

12. Wright $H$, Nicell JA (1999) Characterization of soybean peroxidase for treatment of aqueous phenols. Bioresource Technology 70: 69-79.

13. Maki F, Yugo U, Yasushi M, Isao I (2006) Preparation of peroxidase-immobilized polymers and their application to the removal of environment-contaminating compounds. Bulletin of the Fiber and Textile Research Foundation 15: 15-19.

14. Husain M, Husain Q (2008) Application of redox mediators in the treatment of organic pollutants by using oxidoreductive enzymes: A review. Crit Rev Environ SciTech 38:1-42

15. BayramoÄŸlu G, Arica MY (2008) Enzymatic removal of phenol and p-chlorophenol in enzyme reactor: horseradish peroxidase immobilized on magnetic beads. J Hazard Mater 156: 148-155.

16. Vasileva N, Godjevargova T, Ivanova D, Gabrovska K (2009) Application of immobilized horseradish peroxidase onto modified acrylonitrile copolymer membrane in removing of phenol from water. Int J Biol Macromol 44: 190-194.

17. Kulshrestha $Y$, Husain Q (2006) Direct immobilization of peroxidase on DEAE cellulose from ammonium sulphate fractionated proteins of bitter gourd (Momordica charantia). Enz Microb Technol 38: 470-477.
18. Jamal F, Singh S, Khatoon S, Mehrotra S (2013) Application of Immobilized Pointed Gourd (Trichosanthes dioica) Peroxidase-Concanavalin A Complex on Calcium alginate Pectin Gel in decolorization of synthetic dyes using batch processes and continuous two reactor system. J Bioprocess Biotech 3: 131.

19. Jamal F, Pandey PK, Qidwai T (2010) Potential of peroxidase enzyme from Trichosanthes dioica to mediate disperse dye decolorization in conjunction with redox mediators. J Mol Catal B: Enzy 66: 177-181.

20. Lowry OH, Rosebrough NJ, Farr Al, Randall RJ (1951) Protein measurement with the Folin phenol reagent. J Biol Chem 193: 265-275.

21. Jamal F, Singh S, Qidwai T, Pandey PK, Singh D (2012) Optimization of internal conditions for biocatalytic dye color removal and a comparison of redox mediator's efficiency on partially purified Trichosanthes dioica peroxidase. J Mol Catal B: Enzy 74: 116-124.

22. Akhtar S, Khan AA, Husain Q (2005) Simultaneous purification and immobilization of bitter gourd (Momordica charantia) peroxidases on bioaffinity support. J Chem Technol Biotechnol 80: 198-205.

23. Ashraf H, Husain Q (2009) Removal of $\alpha$-naphthol and other phenolic compounds from polluted water by white radish (Raphanus sativus) peroxidase in the presence of an additive, polyethylene glycol. Biotechnol Bioproc E 14 $536-542$.

24. Musthapa MS, Akhtar S, Khan AA, Husain, Q (2004) An economical, simple and high yield procedure for the immobilization/stabilization of peroxidases from turnip roots. J Sci Ind Res 63: 540-547.

25. Haider T, Husain Q (2007) Calcium alginate entrapped preparations of Aspergillus oryzae $\beta$ galactosidase: its stability and applications in the hydrolysis of lactose. International Journal of Biological Macromolecules 41 : $72-80$

26. Jamal F, Qidwai T, Pandey PK, Singh R, Singh S (2011) Azo and anthraquinone dye decolorization in relation to its molecular structure using soluble Trichosanthes dioica peroxidase supplemented with redox mediator. Catal Commun 12: 1218-1223.

27. Gupta MN, Mattiasson B (1992) Unique applications of immobilized proteins in bioanalytical systems. Methods Biochem Anal 36: 1-34.

28. Qayyum H, Maroof H, Yasha K (2009) Remediation and treatment of organopollutants mediated by peroxidases: a review. Crit Rev Biotechnol 29: 94-119.

29. Tatsumi K, Wada S, Ichikawa H (1996) Removal of chlorophenols from wastewater by immobilized horseradish peroxidase. Biotechnol Bioeng 51 : 126-130.

30. Cheng J, Ming Yu S, Zuo P (2006) Horseradish peroxidase immobilized on aluminium-pillared inter-layered clay for the catalytic oxidation of phenolic wastewater. Water Res 40: 283-290. 